\title{
Increased soil emissions of potent greenhouse gases under increased atmospheric $\mathrm{CO} 2$
}

\author{
Kees Jan van Groenigen, Craig W. Osenberg \& Bruce A. Hungate \\ Nature 475, 214-216 (14 July 2011) doi:10.1038/nature10176
}

\begin{abstract}
Increasing concentrations of atmospheric carbon dioxide (CO2) can affect biotic and abiotic conditions in soil, such as microbial activity and water content 1,2 . In turn, these changes might be expected to alter the production and consumption of the important greenhouse gases nitrous oxide (N2O) and methane (CH4) (refs $2,3)$. However, studies on fluxes of $\mathrm{N} 2 \mathrm{O}$ and $\mathrm{CH} 4$ from soil under increased atmospheric $\mathrm{CO} 2$ have not been quantitatively synthesized. Here we show, using meta-analysis, that increased $\mathrm{CO} 2$ (ranging from 463 to 780 parts per million by volume) stimulates both $\mathrm{N} 2 \mathrm{O}$ emissions from upland soils and $\mathrm{CH} 4$ emissions from rice paddies and natural wetlands. Because enhanced greenhouse-gas emissions add to the radiative forcing of terrestrial ecosystems, these emissions are expected to negate at least 16.6 per cent of the climate change mitigation potential previously predicted from an increase in the terrestrial carbon sink under increased atmospheric $\mathrm{CO} 2$ concentrations4. Our results therefore suggest that the capacity of land ecosystems to slow climate warming has been overestimated.
\end{abstract}

\section{Introduction}

By burning fossil fuels, cutting down forests and changing land use in other ways, humans are rapidly increasing the amount of $\mathrm{CO} 2$ in the atmosphere and warming the planet5. Plant growth is known to increase after an abrupt surge in C02 levels6. Because stimulated assimilation of carbon by plants can increase soil carbon input and soil carbon storage, terrestrial ecosystems could help to reduce the increase in atmospheric $\mathrm{CO} 2$ and thereby slow climate change7. However, the radiative forcing of land ecosystems is not determined by their uptake and release of $\mathrm{CO} 2$ alone; increased $\mathrm{CO} 2$ can also alter soil emissions of $\mathrm{N} 2 \mathrm{O}$ and $\mathrm{CH} 4$ (ref. 2). Although both of these gases occur in far lower atmospheric concentrations than does $\mathrm{CO} 2$, their global warming potentials are much higher: 298 times higher for N2O and 25 times higher for CH4 (ref. 5). Agricultural soils are the main source of human-induced N20 emissions8. Soils under natural vegetation produce roughly the same amount of N20 as all anthropogenic sources combined8. Wetlands, including rice paddies, contribute $32-53 \%$ to the global emissions of CH4 (ref. 8). Upland soils, on the other hand, act as a sink for atmospheric $\mathrm{CH} 4$ through oxidation by methanotrophic bacteria9. Thus, changes in $\mathrm{N} 2 \mathrm{O}$ and $\mathrm{CH} 4$ fluxes could greatly alter how terrestrial ecosystems influence climate 10. 
Studies of greenhouse-gas (GHG) emissions span a variety of ecosystem types, and vary in experimental design and results, making it difficult to determine their global response to increased $\mathrm{CO} 2$ from individual experiments. A quantitative synthesis of results across multiple studies can overcome this problem. Therefore, we used meta-analysis11 to summarize the effect of atmospheric $\mathrm{CO} 2$ enrichment on fluxes of CH4 and N2O from soil, using 152 observations from 49 published studies (see Supplementary Table 1, Supplementary Data 1 and 2, Supplementary Notes 1 ). We also summarized the effect of increased $\mathrm{CO} 2$ on possible drivers of altered $\mathrm{CH} 4$ and $\mathrm{N} 2 \mathrm{O}$ fluxes, using standing root biomass and soil water content from the studies in which the observations on N2O and CH4 fluxes were collected (Supplementary Data 3 and 4). All observations were analysed using three different weighting functions (see Methods). As CH4 and N2O emissions were not correlated with the concentration of $\mathrm{CO} 2$ used for enrichment (Methods), we treat 'increased CO2' as a category.

Overall, increased concentrations of atmospheric CO2 stimulated emissions of N20 by $18.8 \%$ (Fig. 1a). This positive response was significant for studies receiving little or no fertilizer, for non-pot studies and for studies on natural vegetation-that is, studies that most closely resembled real-world conditions (Supplementary Table 2). Increased CO2 stimulated CH4 emissions in wetlands by $13.2 \%$ (Fig. 1a, Supplementary Table 3). In rice paddies, increased CO2 stimulated CH4 emissions by $43.4 \%$ (Fig. 1a, Supplementary Table 4). In upland systems, increased $\mathrm{CO} 2$ caused on average a small and insignificant net uptake of CH4 (Supplementary Table 5). 
Figure 1: Results of a meta-analysis of the response of GHG emissions and their potential drivers to rising levels of atmospheric $\mathrm{CO} 2$.
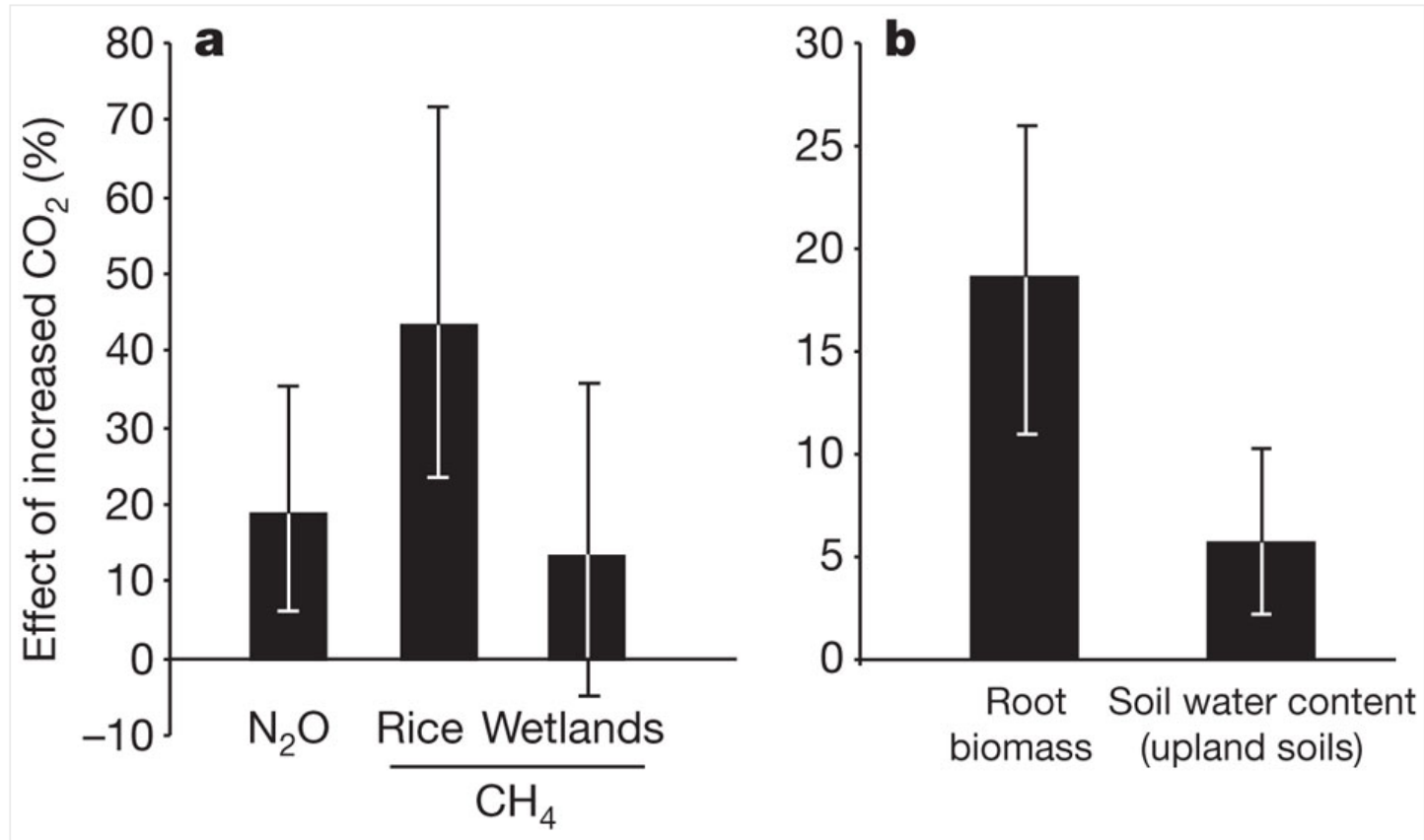

a, The effect of increased $\mathrm{CO}_{2}$ on emissions of $\mathrm{N}_{2} \mathrm{O}$ from upland soil and $\mathrm{CH}_{4}$ from rice paddies and wetlands. Results are based on 73,21 and 24 observations, respectively. b. The effect of increased $\mathrm{CO}_{2}$ on root biomass and soil water content. Results are based on 83 and 55 observations, respectively. Effect sizes in all meta-analvses were weiahted bv renlication. Frror hars. 95\% confidence intervals.

To compare the relative importance of changed GHG fluxes in uplands, wetlands and rice paddies, we expressed the absolute effect of increased $\mathrm{CO} 2$ on $\mathrm{CH} 4$ and N20 fluxes from these ecosystem types (Supplementary Tables 5-8) scaled by their respective total land area. For upland soils, we distinguished fertilized agricultural ecosystems and ecosystems receiving little or no fertilizer. Our estimates of total GHG fluxes under ambient (that is, present-day) $\mathrm{CO} 2$ conditions correspond well to independent global syntheses of modern GHG fluxes (Supplementary Table 9), supporting our scaling approach.

The estimated stimulation by increased CO2 of total soil N2O emissions corresponds to an additional source of $0.33 \mathrm{Pg} \mathrm{CO} 2$ equivalents (equiv.) yr-1 from agricultural ecosystems $(1 \mathrm{Pg}=1015 \mathrm{~g})$, and of $0.24 \mathrm{Pg} \mathrm{CO} 2$ equiv. yr-1 for all other upland ecosystems (Fig. 2). The CO2-stimulation of $\mathrm{CH} 4$ emissions corresponds to an additional source of $0.25 \mathrm{Pg} \mathrm{CO} 2$ equiv. yr-1 from rice paddies and of $0.31 \mathrm{Pg} \mathrm{CO} 2$ equiv. yr-1 from natural wetlands. Our data indicate a small and non-significant effect of $\mathrm{CO} 2$ on global $\mathrm{CH} 4$ fluxes from upland soils for agricultural ecosystems $(0.003 \mathrm{Pg} \mathrm{CO} 2$ equiv. yr-1) and for all other upland ecosystems $(-0.011 \mathrm{Pg}$ CO2 equiv. yr-1). The combined effect of increased $\mathrm{CO} 2$ on emissions of these GHGs is $1.12 \mathrm{Pg}$ CO2 equiv. yr-1.

Figure 2: The effect of rising atmospheric CO2 on GHG emissions, expressed on the global scale. 


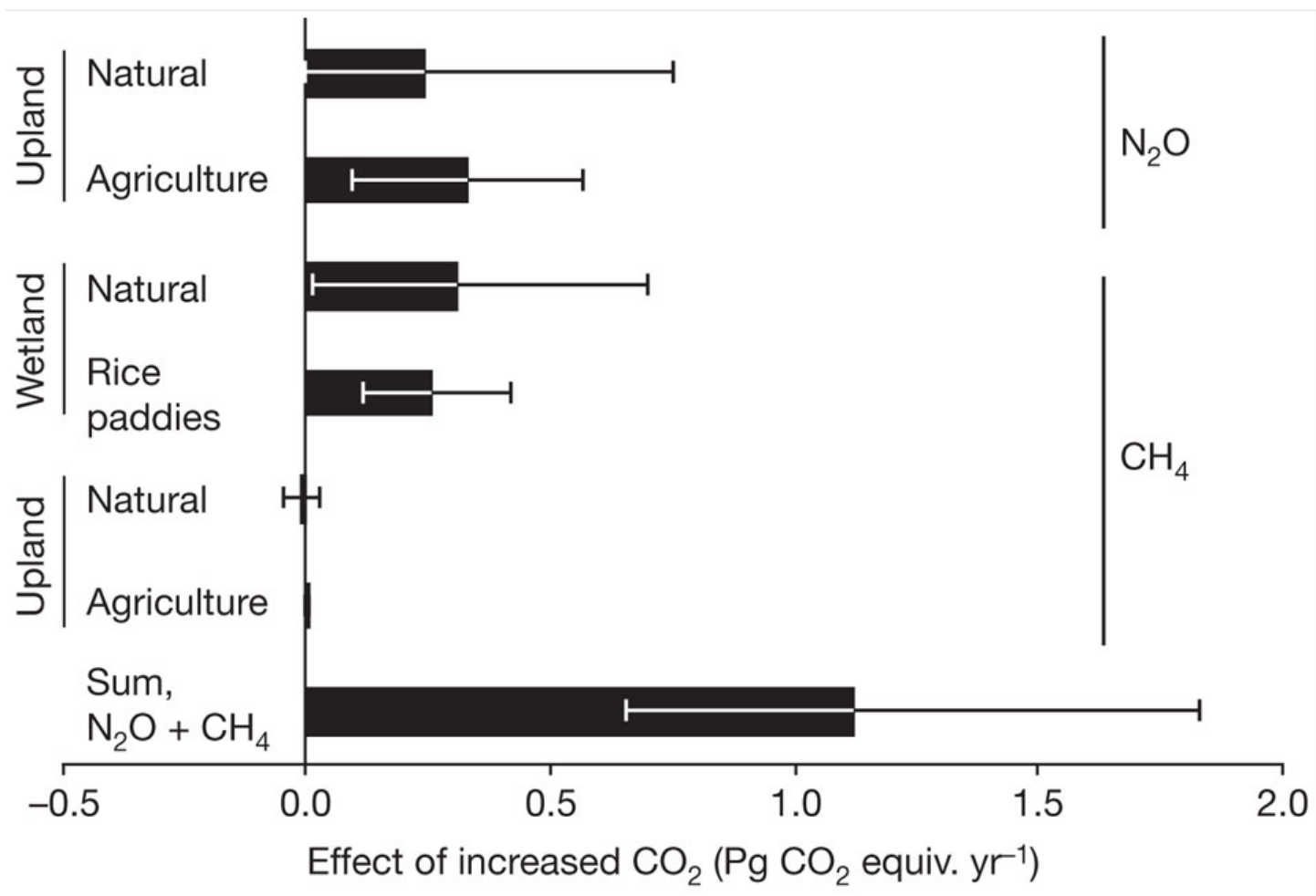

For $\mathrm{N}_{2} \mathrm{O}$ fluxes, the results for natural and agricultural soils were based on 35 and 19 observations, respectively. For $\mathrm{CH}_{4}$ fluxes, the results for natural wetlands, rice paddies, natural upland soils and agricultural upland soils were based on 16, 21, 10 and 8 observations, respectively. Effect sizes in all meta-analyses were weighted by replication. Error bars, $95 \%$ confidence intervals.

Rising atmospheric $\mathrm{CO} 2$ is expected to increase soil C storage in terrestrial ecosystems, which may contribute to the current residual C sink on land7. Metaanalysis of $\mathrm{CO} 2$ enrichment experiments indicates that the sink is larger for ecosystems receiving fertilizer12. Scaled up by the total area of agricultural and non-fertilized ecosystems, these meta-analyses suggest that increased atmospheric CO2 levels may increase the soil C sink by as much as 4.0 Pg CO2 $\mathrm{yr}-1$. Results presented here indicate that enhanced GHG emissions under increased $\mathrm{CO} 2$ reduce the $\mathrm{C}$ mitigation effect of soil $\mathrm{C}$ storage by $28 \%$ (1.12 Pg/4.0 Pg). The magnitude and significance of this result is insensitive to the choice of the weighting function used in the meta-analysis (Supplementary Fig. 1, Supplementary Table 10).

Experiments included in our database increased atmospheric $\mathrm{CO} 2$ concentration to 630 p.p.m.v. on average, a level expected for the second half of this century13. Biogeochemical models predict that at that time, the terrestrial $\mathrm{C}$ sink may be as much as $6.8 \mathrm{Pg} \mathrm{CO} 2 \mathrm{yr}-1$ stronger than it is today4 (when considering forcing by rising $\mathrm{CO} 2$ alone). On the basis of our analysis, a CO2-induced rise in GHG fluxes could negate $16.6 \%$ (1.12 Pg/6.8 Pg) of the expected increase of the entire terrestrial C sink (Supplementary Table 10).

This estimate (16.6\%) is likely to be an underestimate for three reasons. First, most of the studies in our data set measured GHG fluxes during the growing season only, but we assumed these applied to the entire year. Winter emissions 
of $\mathrm{CH} 4$ in wetlands and rice paddies are typically small9; however, winter emissions of $\mathrm{N} 20$ during freeze-thaw cycles can contribute substantially to annual N2O fluxes14, and available data indicate that winter emissions of N2O are stimulated under increased $\mathrm{CO} 2$ (ref. 15). A recently published data set16 suggests that $\mathrm{N} 20$ emissions outside the growing season amount to $88 \%$ and $64 \%$ of the emissions during the growing season in agricultural systems and natural ecosystems, respectively (see Methods). Assuming that increased $\mathrm{CO} 2$ affects N2O emissions proportionately throughout the year, its effect on N2O emissions outside the growing season would therefore amount to $0.29 \mathrm{Pg} \mathrm{CO} 2$ equiv. yr-1 from agricultural systems and 0.15 Pg CO2 equiv. yr-1 from natural ecosystems. Together, these fluxes negate an additional $7 \%$ of the expected increase of the terrestrial $\mathrm{C}$ sink.

Second, atmospheric N deposition is predicted to increase during this century17. Because average $\mathrm{CO} 2$ responses of $\mathrm{N} 2 \mathrm{O}$ emissions were higher in studies receiving additional $\mathrm{N}$ (Supplementary Tables 2 and 6), the positive effect of $\mathrm{CO} 2$ on N2O emissions may strengthen as ecosystems become enriched in N.

Last, CO2 effects on N2O emissions showed a weak but significant correlation with experiment duration (Supplementary Fig. 2), suggesting that $\mathrm{CO} 2$ effects on N20 emissions may increase over time.

Why do GHG emissions respond positively to rising levels of atmospheric CO2? Atmospheric $\mathrm{CO} 2$ enrichment increased soil water contents for the studies contributing to our N20 database (Fig. 1b, Supplementary Table 11); this result is probably due to improved efficiency of water use by plants, which reduces soil water loss through transpiration18. Moreover, increased $\mathrm{CO} 2$ has been shown to enhance soil biological activity across a broad range of ecosystems1, 2. Both responses promote soil anoxia, and thus stimulate denitrification19 (anaerobic microbial respiration of nitrate), one of the major sources of $\mathrm{N} 20$ from soils3. Increased CO2 also enhanced root biomass in all three habitats (Fig. 1b, Supplementary Table 12). As denitrification is generally stimulated by high availability of labile $C$ as a source of energy 20 , and because new $C$ enters mineral soil mainly through the root system, this increase in root biomass would stimulate denitrification rates-and N20 emissions-even further.

Methane is produced only under anaerobic conditions, which are common in soils of rice paddies and natural wetlands but not uplands. Because methanogenic archaea rely on $\mathrm{C}$ assimilation by plants as their ultimate source of organic substrates9, increased rates of soil C input with increased $\mathrm{CO} 2$ can also stimulate $\mathrm{CH} 4$ emissions. Indeed, the positive correlation between $\mathrm{CH} 4$ emission rates and net ecosystem production in wetlands 21 suggests that plant productivity is a key process in the regulation of $\mathrm{CH} 4$ emission from these 
ecosystems. The response to increased $\mathrm{CO} 2$ of $\mathrm{CH} 4$ emissions from rice paddies and wetlands showed significant correlation with the $\mathrm{CO} 2$ response of root biomass ( $\mathrm{r} 2=0.17, \mathrm{P}=0.02$, Supplementary Fig. 6 ); this further suggests that increased $\mathrm{CO} 2$ stimulates $\mathrm{CH} 4$ production through its positive effect on plant growth and soil $\mathrm{C}$ input.

Global changes in climate and atmospheric composition have previously been suggested to affect GHG emissions from natural ecosystems. For instance, a global rise in temperature of $3.4^{\circ} \mathrm{C}$ has been predicted to increase $\mathrm{CH} 4$ emissions from wetlands by $78 \%$ (ref. 22). In addition to its direct effect on the global climate through radiative forcing, our results identify two indirect mechanisms through which rising atmospheric $\mathrm{CO} 2$ amplifies climate change: by stimulating the release of $\mathrm{N} 2 \mathrm{O}$ from terrestrial ecosystems, and by enhancing $\mathrm{CH} 4$ release from wetlands and rice paddies. The meta-analytic approach used here, synthesizing results across 49 studies, shows that increased N2O and CH4 emissions are both general and quantitatively important. Future assessments of terrestrial feedbacks to climate change should therefore consider these indirect effects of increased atmospheric $\mathrm{CO} 2$ on the production by soil of trace gases like $\mathrm{N} 2 \mathrm{O}$ and $\mathrm{CH} 4$.

\section{Methods}

Main Methods References Acknowledgements Author information Supplementary information

\section{Data collection}

We extracted results for soil fluxes of $\mathrm{CH} 4$ and N2O, root biomass and soil water contents from atmospheric $\mathrm{CO} 2$ enrichment studies, conducted in the field, in growth chambers or in glass houses. We used Google Scholar (Google Inc.) for an exhaustive search of journal articles published before January 2011, using as search terms either "elevated CO2" or "CO2 enrichment", and either "N2O" and "soil", or "CH4". Further papers were added from a comparable search using Web of Science. For a study to be included in our data set, the atmospheric CO2 concentration for the ambient and elevated treatments had to be in the range 350-450 p.p.m.v. and 450-800 p.p.m.v., respectively. Means and sample sizes had to be reported for both ambient and elevated CO2 treatments.

For each study, we noted experimental duration, plant species, $\mathrm{N}$ fertilization rates and the type of experimental facility. Estimates of standard deviation were tabulated when available, but were not required for inclusion in the analysis. We included studies involving experiments in pots (that is, any container with dimensions $<1 \mathrm{~m}$ ) or in the field, and studies on natural or planted vegetation. We only considered studies in which soil under both CO2 treatments had the same treatment history. One study was discarded for this reason. Studies on soil water content and root biomass were only included if data on N2O or CH4 fluxes 
were available from the same site. When root biomass and soil water content were reported for multiple soil depths, we calculated the overall treatment effects across the entire soil profile. We included separate observations of increased $\mathrm{CO} 2$ effects from a single ecosystem under different experimental treatments (that is, in multifactorial studies). Because wetlands are mostly anaerobic and therefore produce $\mathrm{CH} 4$, whereas upland soils are mostly aerobic and oxidize $\mathrm{CH} 4$, these two groups of ecosystems were considered in separate data sets. We also distinguished studies conducted in rice paddies, which like wetlands produce $\mathrm{CH} 4$. Because the low number of studies on N2O fluxes from rice paddies (1) and wetlands (3) did not warrant the construction of separate data sets, these studies were not included in our analysis.

We divided the studies into two categories of $\mathrm{N}$ availability based on $\mathrm{N}$ fertilization rates, that is, more or less than $30 \mathrm{~kg} \mathrm{~N}$ ha-1 $\mathrm{yr}-1$. This cut-off point was chosen because it is comparable to maximum atmospheric $\mathrm{N}$ depositions in the US and most of the EU23. We also distinguished between studies on natural or planted vegetation. Agricultural ecosystems were defined as grassland and cropland that received between 30 and $300 \mathrm{~kg} \mathrm{~N}$ ha- $1 \mathrm{yr}-1$. The upper cut-off point was based on reported average fertilization rates for croplands in the world's most intensively fertilized region (that is, East Asia, at $150 \mathrm{~kg} \mathrm{~N}$ ha-1 $\mathrm{yr}-1) 16$, and the assumption that average fertilizer $\mathrm{N}$ use per hectare will be twofold higher in 205030.

\section{Response metrics}

We evaluated our data sets by using meta-analysis. As a metric for the response of GHG emissions to increased CO2, we used the natural log of the response ratio24. This metric starts with an estimate of the relative change in GHG emissions between ambient and increased $\mathrm{CO} 2$ treatments, and log-transforms it to improve its statistical behaviour.

$\operatorname{In} R=\operatorname{In}(\mathrm{GHGi}-\mathrm{GHGa})$

where GHG is the flux of either CH4 or N2O under increased (i) or ambient (a) conditions. We also used $\ln \mathrm{R}$ as a metric for $\mathrm{CO} 2$ responses of root biomass and soil water contents. Fluxes of $\mathrm{CH} 4$ from upland soils could not be analysed using this metric, because our data set included both sites with negative (that is, $\mathrm{CH} 4$ uptake) and positive ( $\mathrm{CH} 4$ emissions) fluxes. For this reason, we also used the difference in annual emissions, expressed on an areal basis (U) as a metric:

$\mathrm{U}=(\mathrm{GHGi}-\mathrm{GHGa})$

with GHGi and GHGa as before. All but one study on wetland soils found net CH4 emissions under both ambient and increased CO2 conditions (Supplementary 
Data 2). This one study, which reported that increased CO2 turned wetland soils from a net sink of $\mathrm{CH} 4$ into a net source, was therefore excluded when calculating $\operatorname{lnR}$, but included when calculating $U$.

Several studies only measured $\mathrm{N} 2 \mathrm{O}$ and $\mathrm{CH} 4$ fluxes during the growing season. In these cases, we assumed that the effect of increased $\mathrm{CO} 2$ on annual fluxes occurred entirely during this period. When the length of the growing season was not explicitly indicated, we assumed a growing season of 150 days. When studies measured gas fluxes for multiple years, fluxes were averaged over time.

\section{Weighting functions}

We performed analyses using non-parametric weighting functions and generated confidence intervals (CIs) on weighted effects sizes using bootstrapping. Because effect size estimates and subsequent inferences in metaanalysis may depend on how individual studies are weighted12, we used three different weighting functions. First, weighted by replication: $\mathrm{WR}=$ (na $\times \mathrm{ni}) /(\mathrm{na}+\mathrm{ni})$, where na and ni are the number of replicates under ambient and increased $\mathrm{CO} 2$, respectively 25 . For pot studies, $\mathrm{n}$ equalled the number of replicate experimental facilities (that is, growth chambers, glass houses, and so on), rather than the number of pots per $\mathrm{CO} 2$ treatment. Second, unweighted. Each observation was assigned an equal weight: $\mathrm{WU}=1$. Third, weighted by the inverse of the pooled variance, the weighting function conventionally used in meta-analyses26: WV = 1/(vara/GHGa2 + vari/GHGi2), with GHGa and GHGi as before, and vara and vari as their respective variance.

When variance estimates were missing for a study, we calculated the average coefficient of variation (CV) within each data set, and then approximated the missing variance by multiplying the reported mean by the average $\mathrm{CV}$ and squaring the result.

When multiple effects were extracted from the same experimental site, we adjusted the weights defined above by the total number of observations from that site. This approach ensured that all experimental comparisons in multifactor studies could be included in the data set without dominating the overall effect size. For three experimental sites, multiple studies were done on the same GHG fluxes at different points in time. We adjusted the weights of observations from these studies by the total number of observations per site. Thus, the final weights used in the analyses were wf,i = Wf,i/nc, where nc was the number of observations from the same site as the ith observation, and $\mathrm{f}$ was the index that referred to one of the three weighting functions defined above. 
Mean effects sizes ( , ) for different categories of studies were estimated as:

We used METAWIN 2.127 to generate these mean effect sizes and 95\% bootstrapped CIs $(4,999$ iterations). Treatment effects were considered significant if the $95 \% \mathrm{CI}$ did not overlap with 0 . The results for the analyses on lnR were back-transformed and reported as percentage change under increased $\mathrm{CO} 2$ (that is, $100 \times(\mathrm{R}-1)$ ) to ease interpretation.

We tested whether $\ln \mathrm{R}$ for GHG emissions was correlated with $\ln \mathrm{R}$ for root biomass using the statistical package SPSS 19. Similarly, we tested whether $\ln R$ for GHG emissions was correlated with experiment duration or the level of $\mathrm{CO} 2$ enrichment. The effect of increased $\mathrm{CO} 2$ on soil emissions of N2O, but not $\mathrm{CH} 4$, showed a weak positive correlation with experiment duration (Supplementary Figs 2 and 3). InR was not significantly correlated with the degree of $\mathrm{CO} 2$ enrichment for either N2O or CH4 emissions (Supplementary Figs 4 and 5). This result is probably due to the large variation in treatment effects between studies, masking effects of the degree in $\mathrm{CO} 2$ enrichment. Alternatively, the results may reflect that plant growth is a saturating function of $\mathrm{CO} 2$ concentrations. Since experiments increased atmospheric $\mathrm{CO} 2$ to a similar extent for all data sets (Supplementary Table 13), we did not normalize effect sizes for the level of CO2 enrichment.

Results using the different weighting functions were qualitatively similar. However, the variance-based weighting function, $\mathrm{Wv}$, yielded weights that varied over 1,000 times in magnitude (Supplementary Data 1 and 2). By assigning extreme importance to individual observations, average effect sizes were largely determined by a small number of studies. Because variance estimates are notoriously unreliable (especially given the small samples common in many of these studies), we favoured the use of the alternative weighting functions (which assigned less extreme weights). In this Letter, we provide results of the analyses on effect sizes that were weighted by replication; results for all weighting functions can be found in Supplementary Tables 2-8, 11 and 12.

\section{Scaling of results}

We scaled up the results from the experiments by multiplying them by the total land area covered by the particular type of habitat that was being summarized. In other words, we took the mean effects and confidence intervals for $\mathrm{U}$ calculated above and scaled them: 
where $\mathrm{F}$ is expressed in $\mathrm{Pg} \mathrm{CO} 2$ equiv. $\mathrm{yr}-1$, and $\mathrm{H}$ is the amount of habitat in uplands, wetlands, or rice paddies (103.1, 5.7, and 1.3 million km2, respectively28, 29). Because $\mathrm{N}$ fertilization increases $\mathrm{N} 20$ emissions16, 17 and enhances plant growth, we distinguished between upland agricultural ecosystems (that is, 19.0 million $\mathrm{km} 2$ of fertilized grasslands and croplands 16 , minus 1.3 million $\mathrm{km} 2$ of rice paddies 28 ) and ecosystems receiving little or no fertilizer $(103.1-19.0+1.3=85.4$ million $\mathrm{km} 2)$.

We estimated the contribution of winter N2O emissions to total N2O emissions from a recently published data set16. For agricultural soils and soils under natural vegetation, studies conducted over the growing season and lasting 100200 days were compared to studies conducted over the entire year (that is, lasting $>300$ days). Because tropical and subtropical systems do not experience marked growing seasons, we excluded studies from those regions. For agricultural soils, we only considered studies on grassland and cropland receiving 30-300 $\mathrm{kg} \mathrm{N}$ ha-1 yr-1 (that is, the same restrictions that applied to our data sets 1 and 2 for the global extrapolation shown in Fig. 2). The difference in mean $\mathrm{N} 20$ emissions between the two categories of study duration was assumed to be representative of $\mathrm{N} 20$ emissions outside the growing season.

To estimate the $\mathrm{CI}$ for the combined effect of increased CO2 on all six GHG fluxes shown in Fig. 2, we calculated the square root of the sum of the squared CIs. Because the original CIs were asymmetric, we did this separately for the upper and lower CIs. All studies on rice paddies were conducted on planted vegetation, experimental conditions resembling real-world conditions. When we combined our extrapolated data to calculate the overall $\mathrm{CO} 2$ effect on $\mathrm{CH} 4$ emissions, we therefore included all available data from rice paddies (Fig. 2, Supplementary Fig. 1). To compare the emissions of GHG with soil C sequestration under increased $\mathrm{CO} 2$, we used results from the analyses weighted by replication and from unweighted analyses as reported in ref. 12, applying the same study selection criteria as for studies in our current data set. These results were expressed as a function of total land area, using the same approach that was used to scale up our results on GHG fluxes.

\section{References}

Zak, D. R., Pregitzer, K. S., King, J. S. \& Holmes, W. E. Elevated atmospheric CO2, fine roots and the response of soil microorganisms: a review and hypothesis. New Phytol. 147, 201-222 (2000)

Pendall, E. et al. Below-ground process responses to elevated $\mathrm{CO} 2$ and temperature: a discussion of observations, measurement methods, and models. New Phytol. 162, 311-322 (2004) 
Smith, K. A. et al. Exchange of greenhouse gases between soil and atmosphere: interactions of soil physical factors and biological processes. Eur. J. Soil Sci. 54, 779-791 (2003)

Thornton, P. E., Lamarque, J.-F., Rosenbloom, N. A. \& Mahowald, N. M. Influence of carbon-nitrogen cycle coupling on land model response to $\mathrm{CO} 2$ fertilization and climate variability. Glob. Biogeochem. Cycles 21 GB4018 doi:10.1029/2006GB002868 (2007)

Forster, P. et al. in Climate Change 2007: The Physical Science Basis (eds Solomon, S. et al.) 129-234 (Cambridge Univ. Press, 2007)

Long, S. P., Ainsworth, E. A., Rogers, A. \& Ort, D. R. Rising atmospheric carbon dioxide: plants FACE the future. Annu. Rev. Plant Biol. 55, 591-628 (2004)

Gifford, R. M. The global carbon cycle: a viewpoint on the missing sink. Aust. J. Plant Physiol. 21, 1-15 (1994)

Denman, K. L. et al. in Climate Change 2007: The Physical Science Basis (eds Solomon, S. et al.) 499-587 (Cambridge Univ. Press, 2007)

Le Mer, J. \& Roger, P. Production, oxidation, emission and consumption of methane by soils: a review. Eur. J. Soil Biol. 37, 25-50 (2001)

Schulze, E. D. et al. Importance of methane and nitrous oxide for Europe's terrestrial greenhouse-gas balance. Nature Geosci. 2, 842-850 (2009)

Osenberg, C. W., Sarnelle, O., Cooper, S. D. \& Holt, R. D. Resolving ecological questions through meta-analysis: goals, metrics, and models. Ecology 80, 11051117 (1999)

Hungate, B. A. et al. Assessing the effect of elevated carbon dioxide on soil carbon: a comparison of four meta-analyses. Glob. Change Biol. 15, 2020-2034 (2009)

Meehl, G. A. et al. in Climate Change 2007: The Physical Science Basis (eds Solomon, S. et al.) 747-845 (Cambridge Univ. Press, 2007)

Matzner, E. \& Borken, W. Do freeze-thaw events enhance C and N losses from soils of different ecosystems? A review. Eur. J. Soil Sci. 59, 274-284 (2008)

Kammann, C., Müller, C., Grünhage, L. \& Jäger, H.-J. Elevated CO2 stimulates N2O emissions in permanent grassland. Soil Biol. Biochem. 40, 2194-2205 (2008)

Stehfest, E. \& Bouwman, L. N2O and NO emission from agricultural fields and soils under natural vegetation: summarizing available measurement data and modelling of global annual emissions. Nutr. Cycl. Agroecosyst. 74, 207-228 (2006)

Galloway, J. N. et al. Transformation of the nitrogen cycle: recent trends, questions, and potential solutions. Science 320, 889-892 (2008) 
Wullschleger, S. D., Tschaplinski, T. J. \& Norby, R. J. Plant water relations at elevated CO2 - implications for water-limited environments. Plant Cell Environ. $25,319-331$ (2002)

Smith, M. S. \& Tiedje, J. M. Phases of denitrification following oxygen depletion in soil. Soil Biol. Biochem. 11, 261-267 (1979)

Weier, K. L., Doran, J. W., Power, J. F. \& Walters, D. T. Denitrification and the dinitrogen/nitrous oxide ratio as affected by soil water, available carbon, and nitrate. Soil Sci. Soc. Am. J. 57, 66-72 (1993)

Whiting, G. J. \& Chanton, J. P. Primary production control of methane emission from wetlands. Nature 364, 794-795 (1993)

Shindell, D. T., Walter, B. P. \& Faluvegi, G. Impacts of climate change on methane emissions from wetlands. Geophys. Res. Lett. 31 L21202

doi:10.1029/2004GL021009 (2004)

Holland, E. A., Braswell, B. H., Sulzman, J. \& Lamarque, J.-F. Nitrogen deposition onto the United States and western Europe: synthesis of observations and models. Ecol. Appl. 15, 38-57 (2005)

Hedges, L. V., Gurevitch, J. \& Curtis, P. S. The meta-analysis of response ratios in experimental ecology. Ecology 80, 1150-1156 (1999)

Adams, D. C., Gurevitch, J. \& Rosenberg, M. S. Resampling tests for meta-analysis of ecological data. Ecology 78, 1277-1283 (1997)

Hedges, L. V. \& Olkin, I. Statistical Methods for Meta-Analysis (Academic, 1985)

Rosenberg, M. S., Adams, D. C. \& Gurevitch, J. METAWIN, Statistical Software for Meta-Analysis Version 2 (Sinauer, 2000)

World Resources Institute. Land area classification by ecosystem type. left fencehttp://earthtrends.wri.org/datatables/index.php?theme=9right fence (2003)

Aselmann, I. \& Crutzen, P. J. Global distribution of natural freshwater wetlands and rice paddies, their net primary productivity, seasonality and possible methane emissions. J. Atmos. Chem. 8, 307-358 (1989)

Tilman, D. et al. Forecasting agriculturally driven global environmental change. Science 292, 281-284 (2001)

Download references

\section{Acknowledgements}

Main Methods References Acknowledgements Author information Supplementary information 
We thank S. A. Prior, G. B. Runion, F. Hagedorn, A. Niboyet, J. C. Blankinship, W. Cheng, T. Kanerva, R. S. Nowak, S. F. Zitzer, F. A. Dijkstra and J. P. Megonigal for sharing their data. Financial support for this study was provided by DOE-NICCR, NSF (DEB-0949460) and the Irish Research Council for Science, Engineering and Technology, co-funded by Marie Curie Actions under FP7.

\section{Author information}

Main Methods References Acknowledgements Author information Supplementary information

\section{Affiliations}

Department of Biological Sciences, Northern Arizona University, Flagstaff, Arizona 86011, USA

Kees Jan van Groenigen \& Bruce A. Hungate

Merriam-Powell Center for Environmental Research, Northern Arizona University, Flagstaff, Arizona 86011, USA

Kees Jan van Groenigen \& Bruce A. Hungate

Department of Botany, School of Natural Sciences, Trinity College Dublin, Dublin 2, Ireland

Kees Jan van Groenigen

Department of Biology, University of Florida, Gainesville, Florida 32611-8525, USA

Craig W. Osenberg

\section{Contributions}

K.J.v.G. and B.A.H. designed the investigation. K.J.v.G. extracted the data from the literature and constructed the database. K.J.v.G. and C.W.O. performed the statistical analyses. All authors contributed to writing the paper.

Competing financial interests

The authors declare no competing financial interests.

Corresponding author

Correspondence to: Kees Jan van Groenigen 